\title{
Total Mineral Material, Acidity, Sulphur and Nitrogen in Rain and Snow at Kentville, Nova Scotia
}

\author{
By F. A. HERMAN and E. GORHAM, Dominion Experimental Station, Kentville, N.S., Canada \\ and Freshwater Biological Association, Ambleside, England
}

(Manuscript received October I, 1956)

\begin{abstract}
Analyses of total ash, sulphur, $\mathrm{pH}$, ammonia and nitrate nitrogen have been made on 23 monthly precipitation samples and 17 individual snow samples collected between June 1952 and May 1954 at Kentville, Nova Scotia, in a predominantly agricultural area. Mean annual supply of total mineral ash was $95 \mathrm{~kg} / \mathrm{ha}$, of sulphur $9.1 \mathrm{~kg} / \mathrm{ha}$, of ammonia nitrogen $2.8 \mathrm{~kg} / \mathrm{ha}$, and of nitrate nitrogen $1.1 \mathrm{~kg} / \mathrm{ha}$. Average $\mathrm{pH}$ was 5.7 , and rains more acid than this exhibited higher levels of both nitrate and sulphur, and a marked correlation between the latter and ammonia.

Snow samples had much lower concentrations of ash, sulphur and nitrogen than rain samples collected in the same months, which may perhaps indicate a lower efficiency of snow flakes in removing materials from the atmosphere.
\end{abstract}

While the nitrogen and sulphur contents of rain have been much investigated (ERIKsson, I952), in view of recent emphasis on worldwide geochemical aspects of atmospheric chemistry it appears highly desirable that information be gathered from as many regions as possible; and in addition local studies may help to clarify the mechanisms by which various elements enter and leave the atmosphere. This paper deals with total ash, $\mathrm{pH}$, sulphur, ammonia and nitrate nitrogen in 23 monthly precipitation samples and 17 individual snow falls at Kentville, Nova Scotia, on the east coast of Canada and in an agricultural district not much subject to industrial air pollution. As well as providing data from an area not hitherto investigated, this study presents a comparison of the concentrations of substances in rain and snow which raises certain problems concerning their relative efficiency in removing materials from the air.

\section{Sampling and analysis}

The analyses were made on a composite sample of each month's precipitation, whether rain or rain and snow, for 23 months between June 1952 and May I954 (excluding March I954); and on I7 individual snow falls in the months November-February (excluding November I953).

Rain samples were collected in a standard metal rain gauge, well-weathered and therefore unlikely to reduce nitrates. Snow samples were taken in a five-gallon pyrex cylinder, from which an aliquot in proportion to the snow fall was added to the holding container for all precipitation, a 2 litre pyrex bottle with three drops of chloroform, stored in the refrigerator. The liquid was allowed to settle clear before aliquots were taken for analysis. For total ash determination samples evaporated in silica dishes were ignited in a muffle furnace at $450-500^{\circ} \mathrm{C}$. Sulphur was estimated gravimetrically as sulphate. $\mathrm{pH}$ was measured by glass electrode and a Beckman meter. Ammonia nitrogen was determined by direct Nesslerization, and nitrate nitrogen by the phenol disulphonic acid method. Losses of nitrate from rain samples have been reported by users of the latter technique, but may well 
have been due to the high acidity of many rain samples. Since the present samples were only faintly acid it is believed that such losses have not been important.

\section{Results}

The average amounts of the various components of the monthly precipitation samples are shown in Table $I$. With a mean monthly rainfall of $80 \mathrm{~mm}$ the supply of mineral ash per month is $7.9 \mathrm{~kg} / \mathrm{ha}$, the minimum for the 23 samples being $1.7 \mathrm{~kg} / \mathrm{ha}$ and the maximum $25.6 \mathrm{~kg} / \mathrm{ha}$. Mean sulphur supply is 0.76 $\mathrm{kg} / \mathrm{ha} /$ month, or $9 . \mathrm{I} \mathrm{kg} / \mathrm{ha} /$ year; similar figures are recorded by ERIKSson (1952) for other North American localities without much atmospheric pollution. The minimum sulphur level was 0.056 and the maximum 2.03 $\mathrm{kg} / \mathrm{ha} /$ month.

Table r. Monthly supply of mineral ash, sulphur, ammonia and nitrate nitrogen in precipitation at Kentville, Nova Scotia

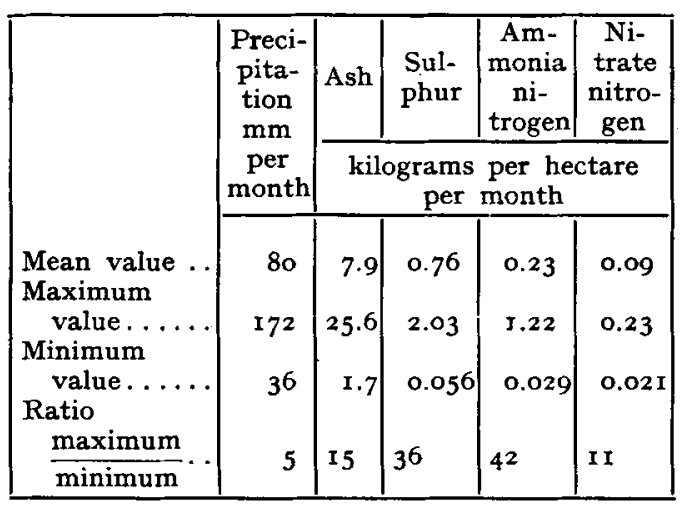

Ammonia nitrogen averages $0.23 \mathrm{~kg} / \mathrm{ha} /$ month, and ranges from 0.029 to $1.22 \mathrm{~kg}$, the mean annual supply being $2.76 \mathrm{~kg} / \mathrm{ha}$. Nitrate nitrogen averages about 40 per cent of ammonia nitrogen, at $0.09 \mathrm{~kg} / \mathrm{ha} / \mathrm{month}$ or $1.08 \mathrm{~kg} / \mathrm{ha} /$ year, the monthly range being 0.021 to $0.23 \mathrm{~kg} / \mathrm{ha}$. These levels of both ammonia and nitrate nitrogen are somewhat low, as is characteristic of places far removed from industry. Just over 60 per cent of the analyses compiled by ERursson (1952) yield higher amounts than the present series, in many cases several times higher.

The ranges of monthly variation in these rain components are rather high, as is demonstrated in Table 1 . While the monthly Tellus IX (1957), 2 rainfall only varies about five-fold from the minimum amount, the maximum nitrate supply is I I times the minimum, and maximum ash is is times the minimum. For sulphur and ammonia nitrogen the ratios of maximum to minimum monthly supply are very high, 36 and 42 respectively.

In a study of composite samples it is difficult to estimate the effect of the amount of precipitation upon the concentrations of various substances in it, but some information may be gained by separating the monthly collections into a "high" and a "low" group. In this instance a level of $70 \mathrm{~mm}$ divides the data into II "low precipitation" and I2 "high precipitation" months, the average fall being $\$ 2$ and $110 \mathrm{~mm}$ respectively, as shown in Table 2. It is evident that the concentrations of all substances but total ash are much greater in the "low" months, so much so that in the case of both sulphur and ammonia nitrogen the supply per unit area per month is much the same in both groups. Acidity is also very much higher in the group of lighter precipitations. Since the precipitation difference between the "low" and "high" months is about two-fold, one might expect a dilution effect of about $0.3 \mathrm{pH}$ units; in fact the latter series exhibits an average $\mathrm{pH}$ of 5.9 as against 5.4 for the former. (The average $\mathrm{pH}$ figures are calculated by converting to concentration and weighting for the amount of precipitation.)

A separation of the most acid from the least acid samples also reveals certain points of interest. In Table 2 the seven most acid and the six least acid precipitations are distinguished from the main body of data, and it is apparent that they differ from one another mainly in their concentrations of acid anions. The less acid series, which is distinctly "alkaline" in relation to the $\mathrm{pH}$ of distilled water in equilibrium with atmospheric carbon dioxide (BARRETt and Brodin, I955), contains only so and 58 per cent respectively of the nitrate nitrogen and sulphur in the more acid group, while ammonia nitrogen and total ash do not differ greatly between the two. Both groups however contain more ash and nitrogen compounds than the intermediate series of $\mathrm{pH}$ $>5.7<6.2$. Both in the monthly precipitations and in the separate snowfalls of $\mathrm{pH} \leqq 5.7$ there is a definite correlation between ammonia nitrogen and sulphur, which is not evident in 
Table 2. Concentrations of mineral material, sulphur, ammonia and nitrate nitrogen, and acidity in monthly precipitation and individual snow samples at Kentville, Nova Scotia

\begin{tabular}{|c|c|c|c|c|c|c|c|}
\hline & Number of & $\begin{array}{l}\text { Precipitation } \\
\text { mm per }\end{array}$ & $\mathrm{pH}$ & Ash & Sulphur & $\mid \begin{array}{c}\text { Ammonia } \\
\text { nitrogen }\end{array}$ & $\begin{array}{r}\text { Nitrate } \\
\text { nitrogen }\end{array}$ \\
\hline & & & & & parts pe & $\mathbf{r}$ million & \\
\hline $\begin{array}{l}\text { All precipitation...... } \\
\text { (I8 per cent snow) }\end{array}$ & 23 & 80 & $5 \cdot 7$ & 9.9 & I.O & 0.29 & $0.1 \mathrm{I}$ \\
\hline $\begin{array}{l}\text { Monthly precipitation } \\
\text { more than } 70 \mathrm{~mm}\end{array}$ & II & I Io & 5.9 & 9.6 & 0.7 & $0.2 \mathrm{I}$ & 0.10 \\
\hline $\begin{array}{l}\text { Monthly precipitation } \\
\text { less than } 70 \mathrm{~mm}\end{array}$ & 12 & $5^{2}$ & $5 \cdot 4$ & I0.6 & $\mathrm{I} .5$ & $0.4^{2}$ & 0.15 \\
\hline $\begin{array}{l}\mathrm{pH} \text { of precipitation.... } \\
5.7 \text { or less }\end{array}$ & 7 & 69 & $5 \cdot 3$ & $\mathbf{r} 3.9$ & I. 2 & 0.36 & 0.20 \\
\hline $\begin{array}{l}\mathrm{pH} \text { of precipitation } . . . \\
6.2 \text { or more }\end{array}$ & 6 & 87 & 6.4 & II $\mathbf{3}$ & 0.7 & 0.38 & o.10 \\
\hline Winter rain $\left\{\begin{array}{l}\text { Nov. to } \\
\text { Feb., except }\end{array}\right.$ & 7 & 60 & 6.7 & 10.5 & 0.7 & $0.4^{\circ}$ & 0.13 \\
\hline J Nov. 1953.. & $\begin{array}{c}17 \\
\text { (7 months) }\end{array}$ & 44 & 5.6 & 2.7 & 0.3 & 0.13 & 0.07 \\
\hline
\end{tabular}

the other samples. The correlation coefficients (" $r$ ") for the seven monthly precipitations and the six individual snow falls are 0.87 and 0.83 respectively.

Seasonal differences are difficult to distinguish in the present series of highly variable data. There is, however, an interesting tendency toward lower sulphur concentrations during the winter months, which suggests that fuelburning at this time is of little importance for the supply of this element in such a rural area. And a most important seasonal difference, between snow and rain, must also be considered. In Table 2 the concentrations of substances in snow are compared with those in rain falling during the same months, November to February, excluding November 1953. (Since only half the total snowfall during these months was analysed separately, it has been necessary to assume that the remaining snowfall was of similar composition in subtracting the snow contribution from the monthly total precipitation figures. This is likely to involve some error, but as the snowfalls analysed covered a representative range of sizes, it is believed that such an assumption will not vitiate the comparisons to be made.) The much lower levels of all substances except hydrogen ions are immediately evident, the difference being greatest in respect of total ash (about $I$ to 4 ) and least in respect of nitrate nitrogen (about $I$ to 2 ).

\section{Discussion}

Perhaps the most interesting feature of these results is the above-mentioned discovery that snow contains much less of most substances than does rain collected over a similar period. This finding would appear to invalidate attempts such as that of VIRO (1953) to calculate the supply of materials in atmospheric precipitation solely on the basis of snow analyses. It also suggests an alternative or additional explanation of the difference in ammonia and nitrate nitrogen recorded by А̊NGSTRöm and HÖGBERG (1952) for precipitation samples from arctic, polar and tropical air. They found that for a given unit of precipitation, samples from polar air contained 74 and 92 per cent as much ammonia and nitrate nitrogen respectively as samples from tropical air, while for arctic air the figures were only 49 and 66 per cent. These results have been taken to indicate that ammonia and nitrate nitrogen are present in the different air masses in these proportions, but if, as seems likely, there were marked differences in the proportions of precipitation falling as snow from the different air masses, then variations in the concentrations of $\mathrm{ma}$ terials in the precipitation might equally well be ascribed to a lesser efficiency of snow flakes in capturing and removing substances from the atmosphere. (Their statement that tropical air contains less nitrogen at higher latitudes might perhaps be susceptible of a similar interpreta- 
tion.) Such a lesser efficiency seems highly probable, since a raindrop presumably has a better chance than a snow flake to envelop, and hence capture, particles with which it comes in contact on its downward path; and solution of gaseous materials, which are probably of much importance in the supply of nitrogen and sulphur compounds, may also be more rapid in the liquid than in the solid phase. Although the greater surface area of the snowflake may lead to more contacts with other particles, its solid surfaces might be expected to militate against their retention. Raindrop evaporation may also be of some importance. Such a difference in efficiency, if real, might also be partially responsible for the observed differences between north and south Sweden in the annual supply of several substances by atmospheric precipitation (EMANUELSSON, ERIKSSON and EGNÉR, I954).

It is of interest that the present results resemble those of ÅNGSTRÖM and HögBeRg in that ammonia nitrogen differs more between rain and snow, and between the different air masses, than does nitrate nitrogen. Moreover, the ratio of ammonia to nitrate nitrogen is lower in both snow and precipitation from arctic air than in rain and precipitation from tropical air.

Since a lower concentration of materials in snow may thus be attributed to two factors not mutually exclusive, i.e. either to low concentration in the air mass from which the snow falls, or to a lesser efficiency of snowflakes in removing materials from the air mass, it would appear to be of considerable interest to determine their relative importance. In this connexion a comparison of the concentrations of substances in wet snow and dry powdery snows might be of value.

The comparison of heavier and lighter monthly precipitations also presents a point of interest, in the fact that the heavier and lighter falls exhibit very similar concentrations of total ash, while the latter show strikingly higher concentrations of ammonia nitrogen and sulphur, and also considerably higher levels of nitrate nitrogen. This might be taken to suggest that a droplet's ability to capture dust particles (which are presumably the main source of ash) is less than its ability to capture the other substances, since the latter are removed to a similar extent by both heavier and lighter precipitations, while the removal of the ash comTellus IX (1957), 2 ponents is more in proportion to the amount of precipitation during the month. Perhaps the difference lies in the smaller amounts of the nitrogen and sulphur compounds in the atmosphere, as well as their greater solubility. In this connexion it is stated by BRUNT (I944) that dust particles are unlikely to act as condensation nuclei, which are in the main watersoluble salts. If so, dust might be little affected by the initial condensation process, and much more by "sweeping-out" during rain or snow fall. It may also be remarked that of all precipitation components investigated, total ash gave the greatest difference between snow and rain.

A last point to be noted is the correlation between ammonia nitrogen and sulphur in the rains and snows of $\mathrm{pH} 5.7$ or less. In these precipitations the ratio of sulphur to ammonia nitrogen averaged 3.3 in the former case and r.4 in the latter; thus ammonia is by no means chemically equivalent to the sulphur in these rains, although nearer the stoichiometric ratio (I.I) in the snow samples. A like correlation, with an average sulphur/ammonia nitrogen ratio of about 2.5, has been recorded by Junge (1954) for aerosols collected in Massachusetts, which he believes to have been supplied by combustion processes. If they were supplied from such processes one might expect them to be acid (cf. GORHAM, I955), and the correlation of the two substances only in the more acid rains at Kentville may lend support to this view.

\section{REFERENCES}

ÁNGSTRÖM, A., and HÖGBERG, L., I952: On the Content of Nitrogen $\left(\mathrm{NH}_{4}-\mathrm{N}\right.$, and $\mathrm{NO}_{3}-\mathrm{N}$ ) in Atmospheric Precipitation. Tellus, 4, pp. $3 \mathrm{I}-42$.

Barrett, E., and Brodin, G., I955: On the Acidity of Scandinavian Precipitation. Tellus, 7, pp. 25I-257.

Brunt, D., 1944: Physical and Dynamical Meteorology. Cambridge University Press.

Emanuelsson, A., Eriksson, E., and Egnér, H., 1954 Composition of Atmospheric Precipitation in Sweden. Tellus, 6, pp. 26I-267.

Errksson, F., I952: Composition of Atmospheric Precipitation. I. Nitrogen Compounds. II. Sulfur, Chloride, Iodine Compounds. Bibliography. Tellus, 4, pp. $215-232$ and $280-303$.

GorhaM, E., I955: On the Acidity and Salinity of Rain. Geochim. et cosmoch. Acta, 7, pp. 231-239.

Junge, C. E., I954: The Chemical Composition of Atmospheric Aerosols. I. Measurements at Round Hill Field Station, June-July r953. J. Met., Ir, pp. 323-333.

VIRO, P. J., I953: Loss of Nutrients and the Natural Balance of the Soil in Finland. Commun. Inst. for. Finland, 42, pp. I-s1. 